\title{
Health Inequalities: Access to Services by Immigrants in Italy
}

\author{
Mara Tognetti \\ University of Milan-Bicocca, Milan, Italy \\ Email: mara.tognetti@unimib.it
}

Received 9 February 2015; accepted 24 March 2015; published 27 March 2015

Copyright (C) 2015 by author and Scientific Research Publishing Inc.

This work is licensed under the Creative Commons Attribution International License (CC BY). http://creativecommons.org/licenses/by/4.0/

c) (i) Open Access

\begin{abstract}
The presence of migrants as a phenomenon of globalization forces the various world health systems to face up to the problem of inequality penalising this population. Although new to immigration, Italy has seen an increase in immigrant health inequalities. Access to health services is a critical issue here.
\end{abstract}

Keywords

Health Inequalities, Immigrants, Racialization, Access to Services

\section{Introduction}

Although public decision-makers and regional health systems have devoted great attention to the issue of equity, the question of what areas of inequality remain and how they may and should be rectified remains an open one.

The same picture is to be found in all western countries: however modern the health system, access to services is far from equal [1] [2]. Differences affect various social groups in the various countries [3]-[5]. The pattern of health inequality applies at the macro level (countries, especially in the same geographical region), the meso level (different socio-economic groups in one and the same nation) [6]-[8], and the micro level (individuals from the same area).

It was the Black Report, published in the United Kingdom in 1980 [9], that exploded the myth that universalistic health systems could reduce inequality between people's health, whether individuals or groups. Another British study [10] revealed how levels of mortality are inversely related to the level of social class.

Back in 1974 the Lalonde Report pointed out that in relation to how societies are organized, and factors emerge that bear more heavily on health than does the actual health system. Hence there is the need to invest in improving the general health conditions.

Persisting health inequalities in the various member countries led the Lisbon European Council 2000 to set 
health inequality as one of its priorities.

Epidemiologists argue [11] that health inequalities are one of the worst scandals of our times, especially in developed democracies. They are also one of the most unfair forms of inequity since health is a prime condition for living life to the full [12]-[14]. Health is a prerequisite for developing all one's potential; it is one of the basic conditions of human life, a major part of human capabilities, calling for prioritization [14].

The most astounding thing about health inequality is how regularly it is reflected in the social scale. Whatever rung one takes, the one below has a less favourable epidemiological profile [1].

Many different factors go to cause disparity in people's health. They are grouped as health determinants [15] and divide into distal determinants, to do with how a society is organized (economy, work, culture, degree of cohesion, role of welfare), and proximal determinants involving factors that bear directly on health (psychosocial background, behavioural and environmental factors, access to an appropriate welfare system).

Health inequalities are thus a highly topical issue of acute concern to our society [6]-[9] [16]. The importance is all the greater in that globalization and migratory flows are leading to new forms of inequality, even in western countries. All western democracies continue to have areas of health inequity and new ones are arising in relation to migrants [17].

Our paper will discuss inequalities affecting migrants in Italy. After a brief summary of the new health inequalities-i.e. those targeting immigrants—we shall focus on certain of these, drawing on the epidemiological data available in Italy.

\section{Health Inequalities among Immigrants}

There is a deep-rooted belief that health is conditioned by genetic factors, lifestyles and the ability of medicine to intervene, but all this takes second place to the impact of changing one's environment.

Ever since the 1970s, studies on migrants have shown that changing country also changed their risk of disease. There are studies on Japanese, for example [18], who crossed the Pacific to settle in Hawaii or California: as they found their feet in American society, they lost their traditional protection from coronary disease and increased their likelihood of stroke, as well as breast, stomach and intestinal cancer [19]. Their social and environmental circumstances bore visibly on their health.

This adds weight to the contention of the Black Report [20] and Lalonde Report [21] that as a society is organized, so do the health risks and potential change for the individuals living in it.

Although health inequalities between different ethnic groups are well documented [22], they tend to lack any framework in theory-a phenomenon which is true of Italy.

The international literature [22] shows how health disparities are a constant of our society, and how within them the health differences are heavily "racialized" and "ethnicized". Racialization of society has become a public reality [17] in that internal frontiers exist based on somatic differences among people. It is precisely in relation to the presence of individuals from other countries that inequalities must be studied, therefore; and no longer just according to categories like social class, profession and nationality, but according to geographical origin and the colour of the skin [17].

From a comparison of the various "racial groups" in America it emerges that the black population has a higher rate of mortality and morbidity for nearly all diseases, shorter life expectancy, minimal access to health care and very low use of modern technology in therapy. Other studies [23] [24] show a higher incidence (37\%) of coronary disease among Afro-American women living in the USA than in women native to the continent (18\%). Again in the United States inequalities have been documented in accessing health treatment, though these have diminished with time [25].

In the United Kingdom it has been shown how economic disadvantage bears on gender and "race" inequalities. Again, studies reveal that the social discriminants of health are perpetuated in various walks of life and produce inequality in life expectancy [26].

Other research indicates the existence of social processes discriminating against various classes of person, including immigrants. Such processes bear on the incidence and severity of disease and access to health services which differ between such groups and the general population, to a degree greater than can be ascribed to ethnic or cultural features [10] [27].

Reproduction of such phenomena is bound up with a set of resources-information, trust, social support-which a person enjoys when belonging to a stable social network [28]. This is borne out by studies showing how the absence of a support network and disequilibrium in social capital [29] comprise a risk factor for health. 
Immigrants, by their very nature, have a limited relational network, of an ethnic kind, since much of their share of social capital has remained in their place of origin.

Cautious though one should be about using the word "race”, the health discriminants and inequalities affecting immigrants must be set down to their geo-cultural provenance, the ethnic factor [6].

For a long time there has been evidence [30] of a "traditional epidemiological approach" whereby, when doctors discover diseases in social groups deemed ethnically or racially different, they tend to see the prime cause as biological or cultural. Other studies [7] show that the most serious inequalities facing immigrants are to do with health. In turn, racial discrimination produces inequalities that affect life expectancy [26]. Population groups that have migrated have a lower life expectancy, on average, than the general population, with higher infant mortality and more frequent ill health [31].

Health inequality studies also indicate the importance of the residence variable, or environmental effect, in relation to those belonging to an ethnic minority who thus tend to end up in less salubrious and lower income jobs and in environmentally depressed areas. Bartley's research [6] suggests that health inequality derives from the socio-economic position and the environment in which people live. It is the immigrant population that settles in zones with the worst services and environmental conditions.

The literature [22] on American whites and blacks distinguishes four models of inequality relating to immigrants:

- the racial-genetic model which divides groups according to phenotypical differences. According to Dessler [22] such studies have found it useful to use the category of ethnic group; the term "race" has no value;

- the health behaviour or lifestyle model. Studies based on this model, Dessler finds, are important but tend to miss the weight of social background;

- the socioeconomic status model. This model likewise has limitations as it may confuse factors of the ethnic group model with those of socio-economic status;

- the social structural model is offered as possibly the best able to distinguish health inequalities between immigrants and native-born persons.

In Italy, too, various authors [32]-[34] have tackled the topic of migrant-related inequalities and racialization of our society, an issue of growing importance. Although as yet there are relatively few studies on immigrant health inequalities, evidence of the phenomenon is mounting [34] [35].

The ethnicizing of inequality is a new issue in Italy but, as Marmot [27] reminds us, the presence of health inequalities, old and new, is a stable transnational phenomenon.

There are Italian authors [32] who argue that social class is a central determinant of inequality, but it is by no means the only relevant factor: gender, ethnicity and age play their part. Others maintain that racial discrimination worsens and compounds the inequality caused by socio-economic adversity [33] [36].

The studies conducted in Italy [37] on attitudes towards immigrants show there to be a hierarchical scale of ethnic branding connected with a scale of values: immigrants are placed on different rungs of the social ladder according to the culture and place they come from. In their turn, Italian authors have remarked on the weight of social capital wherever immigrants encounter inequality [38]. The studies show [33] [39] how Italy too is undergoing a process of racialization which is particularly marked in relation to health inequality, and follows a pattern:

- Although the general healthcare picture of the immigrant population is fairly good, in certain areas of health immigrants fare worse than the native-born, and below the national average [36];

- The time of the healthy migrant-enjoying robust enough health to face the stress of migration-has now given place to the phenomenon of the exhausted migrant whose living and working conditions are taking their toll [40]. There is also a "salmon effect" to be reckoned with, namely the migrant in poor health who decides to go back to his country of origin [40]-[43];

- The main determinants of health and sickness are social: immigrants often work in precarious and harmful conditions, live in hardship, and feel the effects of precariousness and social exclusion.

Some authors [44] attribute this pattern to immigrant working conditions which are generally worse than natives', producing "work malaise”, and also to the kind of relations Italian society and the State have established with this new population.

\section{The Burden of Health Inequalities among Immigrants}

Studying health inequalities as felt by immigrants is a way of measuring the process of racialization in Italy; it 
also gauges the degree of inclusion in the host society [45], as well as immigrants' vulnerability compared with the native-born. In Italy too, therefore, migrant health is important not only as a study in itself, but to understand whether and how far migrants are properly included in society.

The study is not a simple one, given the lack of systematic national, let alone regional, sources. The same picture is found Europe-wide [46]: information on migrant health in Europe is unsystematic; it is hard to monitor and improve their health. In most European countries information on health is not designed in such a way as to distinguish those with migrant status. Likewise studies on health inequalities tend to ignore the immigrant factor [46].

If we observe the health of the immigrant population from systematic sources, we will only be considering people who are detected by those sources, hence only those on the regular files; this is to exclude all others, including those who use informal facilities and the private sector.

The next section will analyse inequalities of access to healthcare services, one of the many forms of health inequity borne by immigrants.

\section{Inequality of Access and Inequality in Access: Data}

The data we possess [47] indicate that the illnesses chiefly affecting immigrants are to do with housing and working conditions, lifestyles, relational difficulties, socialization, and the kind of relations immigrants have with institutions. The connection between housing exclusion and social exclusion is noteworthy, and reflects on health. Migrants also frequently have an unbalanced or defective diet.

Health inequalities linked to access to health resources are significant. As the international [3] [30] [31] and the Italian [34] [45] [48] literature shows, it is difficulty in accessing and using health services that proves so penalising to immigrants' health. For the disadvantaged, such inequalities tend to aggravate the already higher rates of mortality and morbidity than are found in social groups with high socio-economic status. Sen [14] points out that inequalities are not only caused by the distribution of means, but also by a distinction in the ability to gain access. This last may be due to lack of means, but also difficulty in converting available means into actual ability [49]. There are also inequalities to do with the differing systems of health care and specific modes of treatment; this is especially evident when users are familiar with different models of health, disease and health systems [50] from those they have moved into and now encounter as patients.

When it comes to accessing services, much depends on whether the immigrants are aware of their rights and the means of exercising them; whether health workers know of those rights and the procedure for exercising them; and whether there are resources within the health systems for furthering those rights.

Research conducted by the Health Trust of Cesena in 2007 suggested that immigrants have more difficulty than Italians in fitting into welfare pathways, to the detriment of their health. Inequality in accessing services had already been detected by a previous survey (2002-2004).

Studies in Italy [39] [48] have also shown that immigrants' access to services is conditioned by various factors: organizational, cognitive and bureaucratic. This confirms that it is not enough to offer health services and make them claimable: one needs to promote and actively inform if such resources are to become a concrete asset for people coming from different backgrounds with dissimilar welfare provision.

Research carried out at Reggio Emilia [51] into access to health services suggests that immigrants make heavy use of Accident and Emergency (A \& E). This confirmed what the international literature had already detected. Immigrants resort to that service more than natives do because they do not use other services properly. Again, those without regular papers use A \& E more than those officially resident and the native-born, and frequently they do so inappropriately. The same goes for the immigrant young: they access A \& E more often than their native peers.

Nation-wide [35] 5.7\% of immigrants resort to A \& E vs 3.8\% of Italians; $7 \%$ of male immigrants end up there, as compared with $4.2 \%$ of Italian males. The literature suggests a number of variables responsible for this greater access. First of all, immigrants know less about the health services and how they work; they have timetable problems since their working day clashes with the opening times of public services; often they are denied time off work, which increases their delay in contacting the services. They may also have economic problems and baulk at paying the 'ticket'. Territorial services are only apparently easier to use: a population that is not accustomed to using complex resources may do so only partially or not at all.

Lack of a residence permit may also cause a delay in applying for health care. An immigrant may reach 
treatment belatedly when there is no alternative, at which point only A \& E can respond to the emergency without bureaucratic ties. Lastly, that service offers a better likelihood of free treatment, as well as cutting through the delays normally encountered in the public health service. The highly medicalized reception they meet at A \& E gives immigrants the sensation that this is the solution to their health problem and hence they tend to go back there the next time.

Lastly, the heightened emotion of being ill in a migratory situation prompts sufferers to seek an urgent solution, a further reason for using A \& E. It is a well-known facility which also bypasses the booking mechanism.

Other research [20] has argued that immigrants do not look after their health, use the health services less and know little about how they work, hence receive worse treatment than the native-born.

Thus, as well as factors of an economic, social, cultural, political and legal kind, immigrant health discriminants are also bound up with organizational factors. Their health inequalities depend on the quality of health care, the form of access to services, and the kind of treatment the individual undergoes.

They use the territorial services less than natives [34] and this is attributed to various barriers: language, organization, failure to realize the territorial services exist, failure on the part of those services, total or partial.

The reasons prompting Italians to choose a facility for a specialist examination differ from the immigrants' motives [35]. Foreigners are more swayed by the proximity factor than Italians (31.6\% of foreigners vs $22.6 \%$ of Italians). Such convenience counts for more with immigrant men (36.6\%) than for women (28.8\%). We have already mentioned that immigrants find it complex to resort to health services, and all the more if these are far from where they live or work: they are cramped by work restrictions and find it hard to get about in unfamiliar territory. The economic factor counts twice as much with immigrants (19.8\%) as with Italians (8.1\%). The element of trust seems to cause a difference in access, in this case counting for more with Italians (54\% Italians vs $43.1 \%$ foreigners).

The family doctor is an important reference point in people's health decisions. Foreigners, whether men or women, appear to place more trust in this professional (68.6\% foreigners vs 60\% Italians). Italians tend to have more confidence in specialists: the ISTAT 2008 data [35] show that Italians see specialists more frequently than immigrants. The gap is wider for women (27\% of Italian women vs $17 \%$ of foreign women).

In 2005 the Health Ministry performed a survey on foreigners admitted to hospital and found that the immigrant population had only a limited impact on hospital services. Compared to 1998, admissions to day-hospitals had nearly tripled, a sign that immigrants were using services more appropriately. The first four causes of foreign patients being hospitalized were connected with pregnancy and childbirth (normal pregnancy and childbirth $3.7 \%$ vs the national figure of 3.2\%; delivery complications $2.9 \%$ vs $1.2 \%$ nationwide; other pregnancy complications $2.9 \%$ vs $0.7 \%$; loss of blood in pregnancy $1.9 \%$ vs $0.6 \%$ ). This applied to natives and immigrants alike (63.3\% Italians vs 60.6\% immigrants).

The rate of hospitalization [52] was higher for Italians than immigrants (216\%o the former, 139\%o the latter). This is partly due to the immigrant population being younger.

As regards the normal hospital admission rate for acute conditions, it emerges that for foreign citizens this is 119\%o (118\%o for foreign citizens, and 129\%o for EU citizens), as compared with the overall Italian rate of $167 \%$ - which means there is lower ordinary admission of immigrants.

On interesting fact is the low rate of ordinary admission on the part of immigrants (101\%o vs 147\%o Italians), and even lower (never more than 1\%) when it comes to clandestine immigrants.

The percentage of ordinary admissions in a state of emergency is higher for immigrants than native-born. Admission in such a state may be seen as a proxy for the use of territorial health services and the ability of those services to look after the patient. Emergency admission also implies: a severe problem, little knowledge about or use of territorial services by immigrants, little information about and malfunction by territorial services. The factors behind emergency admission also include [34] cold weather, unhealthy diet, precarious work and social position, over-crowded primitive living conditions, adjustment stress (mental health, alcoholism, substance dependency).

Other research [53] shows that immigrant hospitalization may be due to physiological conditions (such as pregnancy and childbirth if women, or accident and trauma if men). It is confirmed that access to health services is connected with emergency treatment for both women (childbirth) and men (trauma).

The data described suggest that immigrant men and women differ in their use of services, and that Italians differ from foreigners. Immigrants confine their use of health facilities to a few services. Going by national data and official sources, we cannot gauge certain variables that the still rare local research sees as decisive for access 
to health services, such as linguistic skill and length of stay in Italy. These two factors are claimed by researchers [46] as weighing on access, along with legal status. As these variables increase, so does access to services. Other factors deter from access: the extra cost of treatment (ticket, etc.), hours of service opening and functioning, complicated bureaucracy. The official statistics fail to pick up these variables.

Though limited and by no means exhaustive, the empirical evidence presented so far suggests that immigrants make insufficient and inappropriate use of health services, and that acute inequity of access continues to divide migrants from native-born.

\section{Conclusions}

The data we have discussed on inequalities penalising migrants are a novelty for Italy and confirm that a process of racialization is afoot.

The data show that the way of reducing health inequality for migrants must involve eliminating social inequity. The health system and its workers ought to pay special attention to this population whose prospects of migration depend on their health capital.

A country that sees the removal of health inequalities as a goal of citizenship must also acquire systematic data bearing in mind the specific conditions of immigration. It is becoming more and more important to create a set of indicators geared to the immigrant population and its health needs, based on: hospitalization patterns, maternity and child health, accident at work, trauma, infectious diseases and mortality. Side by side with the training and sensitization of health workers, we need more studies and research into health inequalities relating to immigrants. National and local official sources of information need improving so as to prevent the epidemiological picture from only covering the officially registered part of facility users.

\section{References}

[1] Marmot, M. and Wilkinson, G. (1999) Social Determinants of Health. Oxford University Press, Oxford.

[2] Gulliford, M. and Morgan, M. (2003) Access to Health Care. Routledge, London.

[3] Van Doorslaer, E. and Masseria, C. (2004) Income-Related Inequality in the Use of Medical Care in 21 OECD countries. OECD, Paris. http://dx.doi.org/10.1787/687501760705

[4] Kunst, A.E. and Mackenbach, J.P. (1992) An International Comparison of Socio-Economic Inequalities in Mortality. MGZ 92.11, Department of Public Health and Social Medicine, Erasmus University Rotterdam, Rotterdam.

[5] Bago d'Uva, T.B. and Jones, A.M. (2009) Health Care Utilisation in Europe: New Evidence from the ECHP. Journal of Health Economics, 28, 265-279. http://dx.doi.org/10.1016/j.jhealeco.2008.11.002

[6] Bartley, M. (2004) Health Inequality: An Introduction to Theory, Concepts and Methods. Polity Press, Cambridge.

[7] Leclerc, A., Kamiski, M. and Lang, T. (2008) Inégaux face à la santé. La Découverte-Inserm, Paris.

[8] Terraneo, M., Simone, S. and Tognetti Bordogna, M. (2014) Social Inequalities and Pharmaceutical Cost Sharing in Italian Regions. International Journal of Health Services, 44, 761-785. http://dx.doi.org/10.2190/HS.44.4.e

[9] Blane, D. (1985) An Assessment of the Black Report's Explanations of Health Inequalities. Sociology of Health and Illness, 7, 423-445. http://dx.doi.org/10.1111/1467-9566.ep10832355

[10] Acheson, D. (1998) Independent Inquiry into Inequalities in Health Report. The Stationery Office, London.

[11] Marmot, M. and Wilkinson, R.G. (2001) Psychosocial and Material Pathway in the Relation between Income and Health: A Response to Lynch et al. British Medical Journal, 322, 1233-1236. http://dx.doi.org/10.1136/bmj.322.7296.1233

[12] Daniels, N. (1985) Just Health Care. Cambridge University Press, Cambridge. http://dx.doi.org/10.1017/CBO9780511624971

[13] Anand, S. (2004) The Concern for Equity in Health. In: Anand, S., Fabienne, P. and Sen, A.K., Eds., Public Health, Ethics, and Equity, Oxford University Press, Oxford, 258-264.

[14] Sen, A. (2005) Human Rights and Capabilities. Journal of Human Development and Capabilities, 6, 151-166. http://dx.doi.org/10.1080/14649880500120491

[15] Breilh, J. (1979) Epidemiología: Economia, Medicina e Política (Epidemiology: Economics, Medicine and Politics). Fontamara, Mexico City.

[16] Macintyre, S., Ellaway, A. and Cummins, S. (2002) Place Effects on Health: How Can We Conceptualise, Operationalise and Measure Them? Social Science and Medicine, 55, 125-139. http://dx.doi.org/10.1016/S0277-9536(01)00214-3 
[17] Fassin, D. (2006) La biopolitica dell'alterità (The Biopolitics of Otherness). In: Quaranta, I., Ed., Antropologia Medica, Raffaello Cortina, Milan, 303-323.

[18] Marmot, M., Syme, S.L., Kagan, A., Kato, H., Cohen, J.B. and Belsky, J. (1975) Epidemiologic Studies of Coronary Disease and Stoke in Japanese Men Living in Japan, Hawaii and California: Prevalence of Coronary and Hypertensive Heart Disease and Associated Risk Factors. American Journal of Epidemiology, 102, 514-525.

[19] Kolonel, L.N., Hinds, M.W. and Hankin, J.H. (1980) Cancer Patterns among Migrants and Native-Born Japanese in Hawaii in Relation to Smoking, Drinking and Dietary Habits. In: Gelboin, H.V., Mac Mahon, B., Matsushima, T., Sugimura, T., Takayama, S. and Takebe, H., Eds., Genetic and Environmental Factors in Experimental and Human Cancer, Scientific Societies Press, Tokyo, 327-340.

[20] DHSS (Black Report) (1980) Inequalities in Health: Report of a Research Working Group. Department of Health and Social Security, London. http://www.sochealth.co.uk/history/black.htm

[21] Lalonde, M. (1974) A New Perspective on the Health of Canadians. A Working Document, Minister of National Health and Welfare, Ottawa.

[22] Dressler, W.W. (1993) Health in the African American Community: Accounting for Health Inequalities. Medical Anthropology Quarterly, 7, 325-345.

[23] Heymsfield, S., et al. (1977) Race, Education and Prevalence of Hypertension. American Journal of Epidemiology, 106, 351-361.

[24] Ford, E.S. and Cooper, R.S. (1991) Risk Factors for Hypertension in a National Cohort Study. Hypertension, 18, 598606.

[25] Jaynes, G.D., Williams, R.M., Eds. (1989) A Common Destiny: Blacks and American Society. National Academy Press, Washington DC.

[26] Wilkinson, R.G. (1996) Unhealthy Societies: The Afflictions of Inequality. Routledge, London. http://dx.doi.org/10.4324/9780203421680

[27] Marmot, M. (2004) Status Syndrome. Bloomsbury, London.

[28] Cohen, S., Gottlieb, B.H. and Underwood, L.G. (2000) Social Relationship and Health. In: Cohen, S., et al., Eds., Social Support Measurement and Intervention: A Guide for Health and Social Scientists, Oxford University Press, New York, 147-156.

[29] Diez Roux, A.V., Merkin, S.S., Arnett, D., Chambless, L., Massing, M., Nieto, F.J., et al. (2001) Neighbourhood of Residence and Incidence of Coronary Heart Disease. The New England Journal of Medicine, 345, 99-106.

[30] Nazroo, J. (1997) The Health of Britain’s Ethnic Minorities. Policy Studies Institute, London.

[31] Nazroo, J. and Williams, D.R. (2006) The Social Determination of Ethnic/Racial Inequalities in Health. In: Marmot, M. and Wilkinson, R.G., Eds., Social Determinant of Health, Oxford University Press, Oxford, 76-83.

[32] Gallino, L., Ed. (1993) Disuguaglianza ed equità in Europa (Inequality and Equity in Europe). Laterza, Bari.

[33] Tognetti Bordogna, M., Ed. (2008) Immigrazione e disuguaglianza di salute (Immigration and Health Imequality). Franco Angeli, Milan.

[34] Nuti, S., Maciocco, G. and Barsani, S., Eds. (2012) Immigrazione e salute. Percorsi d'integrazione sociale (Immigration and Health. Social Integration Pathways). Il Mulino, Bologna.

[35] ISTAT (2008) Sanità. Statistiche in breve, Salute e ricorso ai servizi sanitari della popolazione straniera residente in Italia (Health and Recourse to Health Services by the Foreign Population Resident in Italy). 11 December.

[36] Marceca, M., Geraci, S. and Martino, A. (2006) Esperienza migratoria, salute e disuguaglianze (Migratory Experience, Health and Inequalities). Osservatorio Italiano sulla Salute Globale-OISG. In: A caro prezzo. Secondo rapporto sulle disuguaglianze (At a High Price. Second Report on Inequalities), ETS, Pisa, 304-318.

[37] Piemonte, I., Ed. (1992) Rumore. Atteggiamenti verso gli immigrati stranieri (Noise. Attitudes to Foreign Immigrants). Rosenberg \& Sellier, Turin.

[38] Bianco, M.L. (2001) L’Italia delle disuguaglianze (The Italy of Inequalities). Carocci, Rome.

[39] Padovan, D. and Alietti, A. (2008) Disuguaglianze nelle minoranze etniche: Una ricerca in due presidi ospedalieri della provincia torinese (Inequaalities in Ethnic Minorities: Research in Two Hospitals in the Province of Turin). In: Tognetti Bordogna, M., Ed., Disuguaglianze di salute e immigrazione (Health Inequalities and Immigration), Franco Angeli, Milan, 135-162.

[40] Bollini, P. and Sien, H. (1995) No Real Progress towards Equity: Health of Migrants and Ethnic Minorities on the Eve of the Year 2000. Social Science \& Medicine, 41, 819-828. http://dx.doi.org/10.1016/0277-9536(94)00386-8

[41] Razum, O. (2006) Commentary: Of Salmon and Time Travellers-Musing on the Mystery of Migration Mortality. International Journal of Epidemiology, 34, 919-921. http://dx.doi.org/10.1093/ije/dyl143 
[42] Razum, O., Zeeb, H. and Rohrmann, S. (2000) The Healthy Migrant Effect-Not Merely a Fallacy of Inaccurate Denominator Figures. International Journal of Epidemiology, 29, 191-192. http://dx.doi.org/10.1093/ije/29.1.191

[43] Ullmann, S.H., Goldman, N. and Massey, D.S. (2011) Healthier before They Migrate, Less Healthy When They Return? The Health of Returned Migrants in Mexico. Social Science \& Medicine, 73, 421-428. http://dx.doi.org/10.1016/j.socscimed.2011.05.037

[44] Perocco, F. (2012) Trasformazioni globali e nuove disuguaglianze. Il caso Italia (Global Transformations and New Inequalities. The Case of Italy). Franco Angeli, Milan.

[45] Tognetti Bordogna, M. (2012) Accesso ai servizi sanitari e costruzione della cittadinanza dei migranti (Access to Health Services and Building Migrant Citizenship). Autonomie locali e Servizi Sociali, 1, 111-124.

[46] Rechel, B., Mladovsky, P., et al. (2013) Migration and Health in an Increasingly Diverse Europe. The Lancet, Published on Line.

[47] AGENAS (2011) La spesa sanitaria per gli immigrati (Health Spending on Immigrants). Age.na.s.on line, March.

[48] Tognetti Bordogna, M., Ed. (2004) I colori del welfare (The Colours of Welfare). Franco Angeli, Milan.

[49] ASR, Regione Emilia Romagna (2007) Disuguaglianze in cifre (Inequalities in Figures). Dossier n. 145.

[50] Kleiman, A. (1980) Patient and Healer in the Context of Culture. California Press, Berkley.

[51] AA.VV (2011) L’accesso al Pronto Soccorso nella Provincia di Reggio Emilia: Un confronto tra la popolazione immigrata e italiana (Access to Accident \& Emergency in the Province of Reggio Emilia: A Comparison between the Immigrant and the Italian Population. Epidemiologia e Prevenzione, 3, 250-266.

[52] AA.VV (2008) La spesa sanitaria per gli immigrati (Health Spending on Immigrants). In Monitori, n. 21.

[53] ISTISSAN (2005) Rapporto ISTISSAN. Istituto Superiore di Sanità, Rome. 